\title{
Could Tocilizumab be an Attractive Therapeutic Option for Elderly Patients with Severe COVID-19? A Case Report
}

\author{
Caroline Streicher ${ }^{1}$ (D) Xavier Engalenc $^{2} \cdot$ Marion Gaudin $^{2} \cdot$ Guillaume Vignaud $^{2} \cdot$ Annick Daulange $^{1}$. \\ Bruno Abraham ${ }^{2}$
}

Published online: 20 September 2020

(c) Springer Nature Switzerland AG 2020

A new coronavirus was first identified in December 2019 in Hubei province, China. This severe acute respiratory syndrome coronavirus 2 (SARS-CoV-2) spread rapidly and became a large worldwide pandemic [1]. The coronavirus disease (COVID-19) caused by SARS-CoV-2 is associated with common symptoms including asthenia, fever, cough and lymphopenia. However, about 15-25\% of COVID-19 patients develop severe infection characterised by acute respiratory distress syndrome leading to multiple organ dysfunction and death [2]. Early analysis of patients who died from severe COVID-19 show elevated inflammatory cytokine levels and suggest the involvement of a cytokine storm also called cytokine release syndrome (CRS). CRS is an abnormal immune response, which can be triggered by infection and characterised by a considerable release of proinflammatory cytokine, including interleukin 6 (IL-6), granulocyte-colony stimulating factor and tumour necrosis factor $\alpha$. First analysis showed that patients with severe COVID19 presented significantly higher levels of IL- 6 and other cytokines associated with severe lymphopenia. This abnormal activation of the immune system seems to be combined with an increase in vascular permeability resulting in tissue necrosis with monocyte infiltrations in multiple organs $[3$, 4]. This evidence suggests that CRS might play an immune damaging role in patients with severe COVID-19. Moreover, clinical data showed that high levels of IL-6 are correlated with COVID-19 severity and mortality [5]. Therefore,

Caroline Streicher

caroline.streicher@ch-brive.fr

1 Unité de préparation et de contrôle pharmaceutique (UPCP), Centre Hospitalier de Brive La Gaillarde, 1 boulevard du Dr Verlhac, 19312 Brive la Gaillarde Cedex, France

2 Médecine interne et Maladies infectieuses, Centre Hospitalier de Brive La Gaillarde, 1 boulevard du Dr Verlhac, 19312 Brive la Gaillarde Cedex, France targeting IL-6 could be an attractive therapy option for the treatment of severe COVID-19 patients.

Tocilizumab is a recombinant monoclonal antibody, which binds specifically to both soluble and membranebound IL-6 receptors. Tocilizumab is currently used for a variety of immune system diseases; however, it recently obtained a new indication for the treatment of CRS induced by CAR-T cell therapy [6]. To date, no therapy has been approved for the treatment of COVID-19, but targeting IL-6 with tocilizumab treatment could be a potential therapeutic option for patients with COVID-19-induced CRS [3, 7-10].

Indeed, the first Chinese and Italian data suggest that tocilizumab could be an efficient treatment for patients with severe COVID-19 and CRS. In their studies, administration of tocilizumab was associated with the improvement of patients' clinical symptoms, characterised by a decrease in fever, an improvement of respiratory function with lower oxygen requirements and a reduction in mortality [11-14].

Recently, there have been an increased number of studies on the use of tocilizumab treatment for severe COVID-19 patients, but more information is needed on its effectiveness and safety, notably for the treatment of elderly patients.

In this case, we describe the successful treatment by tocilizumab of an 87-year-old patient with severe COVID-19. The patient's informed consent was obtained before the offlabel use of tocilizumab.

An 87-year-old male, with suspected COVID-19 disease, was admitted to our COVID-19 unit. For about 1 week, he presented a cough, breathing difficulties and fever $\left(>39^{\circ} \mathrm{C}\right)$. The patient had no specific co-morbidities, he had been treated for prostate and lung cancer, respectively, in 2008 and 2013. Because of a pulmonary embolism in 2013, he was still on an oral anticoagulation treatment. The complete list of drugs taken by the patient included: fluindione $15 \mathrm{mg} /$ day, pantoprazole $40 \mathrm{mg} /$ day, ciprofibrate $100 \mathrm{mg} /$ day and zopiclone $3.75 \mathrm{mg} /$ day. 
To confirm the COVID-19 infection, SARS-Cov-2 realtime polymerase chain reaction test was carried out and returned positive. The chest CT scan revealed bilateral ground glass opacities with "crazy paving" very suggestive of COVID-19 infection. The lung damage was severe with $50-75 \%$ of areas affected.

The patient became more and more dyspnoeic and required oxygen supplementation $(10 \mathrm{~L} / \mathrm{min})$. Prophylactic antibiotic treatment by amoxicillin/clavulanic acid infusions ( $3 \mathrm{~g} /$ day) and intravenous paracetamol ( $3 \mathrm{~g} /$ day) were introduced. The oral anticoagulation treatment was switched to tinzaparin subcutaneous injection (16,000 UI/day).

At the same time, blood sample analysis found elevated levels of C-reactive-protein (CRP $186 \mathrm{mg} / \mathrm{L}$ ) a high marker of inflammation, a hyperferritinaemia $(2257 \mathrm{ng} / \mathrm{mL})$, and a lymphopenia $\left(0.52 \times 10^{9} / \mathrm{L}\right)$. Unfortunately, neither IL-6 nor other cytokine levels could be measured in our laboratory. Due to a suspicion of COVID-19-induced CRS, the choice of tocilizumab treatment was discussed and validated in a multidisciplinary meeting with infectologists and internists.

The patient received a first dose of intravenous tocilizumab at $8 \mathrm{mg} / \mathrm{kg}$ with no clinical improvement. Approximately $12 \mathrm{~h}$ later, a second infusion was given, at the same dose, without any side effects. No corticosteroid treatment was given to the patient.

One day after the tocilizumab infusion, pulmonary auscultation was clearer with an improvement in bilateral crackles. The patient was rapidly afebrile, but he still required 15 $\mathrm{L} / \mathrm{min}$ of oxygen (Table 1). At Day 3, the CRP decreased to $77 \mathrm{mg} / \mathrm{L}$ and returned to normal value at Day 8 . Time to oxygen weaning took longer, and it was 1 week after tocilizumab, that oxygen flow could be progressively reduced: 10 L/min on Day 8, 6 L/min on Day 10, 3 L/min on Day 12. About 2 weeks after tocilizumab infusion, antibiotics were stopped, the oxygen flow was reduced to $1 \mathrm{~L} / \mathrm{min}$ and the patient's general condition improved. The chest scan showed a stable lung impairment with interstitial syndrome sequelae. Eighteen days after the tocilizumab infusion, the patient was discharged with normal CRP and lymphocyte values and with a significant reduction in oxygen requirements.

In this case, we describe a successful treatment by tocilizumab of an 87-year-old male. Clinical data show that the patient's respiratory function improved after tocilizumab treatment. Moreover, a significant decrease of CRP and ferritin levels was observed just after the two infusions, suggesting the potential impact of tocilizumab on the cytokine storm. Unfortunately, inflammatory cytokine levels could not be measured either before or after tocilizumab treatment.

Nevertheless, similar results were described in literature data and showed the improvement of patients' conditions after tocilizumab treatment [11-15]. Recently, results of CORIMUNO-TOCI, the first randomised clinical trial, were announced in a press release. The study included 129 patients with COVID-19, 65 of whom received tocilizumab associated with standard symptomatic treatment, and 64 received only the standard treatment. Results show that tocilizumab significantly improves the prognosis of patients and confirm the benefit of tocilizumab for the treatment of moderate and severe COVID-19 patients [16].

In our case report, no severe adverse drug reaction was reported by the patient, suggesting a favourable safety profile, even for elderly patients. Two weeks after the tocilizumab infusion, the patient's neutrophil count was decreased slightly with no incidence of infection. However, Guaraldi et al., in their retrospective study, observed a significantly higher prevalence of infection in the tocilizumab group than in the standard-of-care group [14]. For that reason, Zhang et al. recommended a safety monitoring of tocilizumab use. Tocilizumab should be used with caution in patients with a neutrophil count $<2 \times 10^{9} / \mathrm{L}$, a

Table 1 Outcome of patient with COVID-19 before and after tocilizumab

\begin{tabular}{|c|c|c|c|c|c|c|c|}
\hline & $\begin{array}{l}\text { Before toci- } \\
\text { lizumab }\end{array}$ & $\begin{array}{l}\text { Day } 1 \text { after } \\
\text { tocilizumab }\end{array}$ & $\begin{array}{l}\text { Day } 3 \text { after } \\
\text { tocilizumab }\end{array}$ & $\begin{array}{l}\text { Day } 8 \text { after } \\
\text { tocilizumab }\end{array}$ & $\begin{array}{l}\text { Day } 10 \text { after } \\
\text { tocilizumab }\end{array}$ & $\begin{array}{l}\text { Day } 12 \text { after } \\
\text { tocilizumab }\end{array}$ & $\begin{array}{l}\text { Day } 18 \text { after } \\
\text { tocilizumab }\end{array}$ \\
\hline C-reactive-protein (mg/L) & 186 & 175 & 77 & $<5$ & $<5$ & $<5$ & $<5$ \\
\hline Ferritin $(\mathrm{ng} / \mathrm{mL})$ & 2257 & - & - & - & 159 & - & - \\
\hline Leukocyte count $\left(\times 10^{9} / \mathrm{L}\right)$ & 8.63 & 5.78 & 4.43 & 6.88 & 7.7 & 4.18 & 3.58 \\
\hline Neutrophil count $\left(\times 10^{9} / \mathrm{L}\right)$ & 7.64 & 5.25 & 3.57 & 4.98 & 5.78 & 2.08 & 1.54 \\
\hline Lymphocyte count $\left(\times 10^{9} / \mathrm{L}\right)$ & 0.52 & 0.27 & 0.60 & 0.98 & 1.12 & 1.12 & 1.09 \\
\hline Oxygen requirement $(\mathrm{L} / \mathrm{min})$ & 9 & 10 & 15 & 15 & 10 & 5 & 2 \\
\hline $\mathrm{FiO}_{2}$ & $56 \%$ & $60 \%$ & $80 \%$ & $80 \%$ & $60 \%$ & $40 \%$ & $28 \%$ \\
\hline Blood oxygen saturation & $94 \%$ & $92 \%$ & $93 \%$ & $93 \%$ & - & $99 \%$ & $96 \%$ \\
\hline $\mathrm{PaO}_{2}(\mathrm{mmHg})$ & 64 & 59 & 64.2 & 85.8 & - & 162 & 71.1 \\
\hline $\mathrm{PaCO}_{2}(\mathrm{mmHg})$ & 30 & 46.2 & 37.8 & 33.3 & - & 36.7 & 32.6 \\
\hline $\mathrm{PaO}_{2} / \mathrm{FiO}_{2}(\mathrm{mmHg})$ & 96 & 98 & 80 & 107 & & 405 & 253 \\
\hline
\end{tabular}

$\mathrm{FiO}_{2}$ fraction of inspired oxygen, $\mathrm{PaO}_{2}$ partial pressure of oxygen, $\mathrm{PaCO}_{2}$ partial pressure of carbon dioxide 
platelet count $<100 \times 10^{3} / \mu \mathrm{L}$ or liver transaminase above a 1.5 -fold upper limit of normal. For patients with a neutrophil count $<0.5 \times 10^{9} / \mathrm{L}$, a platelet count $<50 \times 10^{3} / \mu \mathrm{L}$ or liver transaminase above a fivefold upper limit of normal, tocilizumab should be avoided [17].

Because our study is a case report, it has some limitations. However, to our knowledge, it is the first case report that describes the use of tocilizumab in a patient aged $>80$ years with severe COVID-19. Unfortunately, elderly patients are often excluded from clinical trials while we need effectiveness and safety data in this population. All over the world, clinical trials with tocilizumab are still underway and should provide additional results [5]. The dose schedule of tocilizumab treatment remains to be validated, and more information is needed regarding which patients may benefit most from tocilizumab. This treatment is relatively expensive so for that reason eligibility criteria should be defined. There is currently no consensus on whether IL-6 level should be measured before and after tocilizumab treatment, nor whether CRP monitoring could be a good biomarker to assess the drug efficacy. Finally, clinical trial results would inform us whether tocilizumab should be associated with other therapeutic options such as corticosteroids, immunosuppressive drugs or antiviral agents.

Tocilizumab appears to be an attractive therapeutic option for patients with COVID-19-induced CRS, even in elderly patients. The benefit of tocilizumab treatment remains to be validated by randomised controlled trials to confirm the effectiveness and safety of this drug in the elderly population.

\section{Declarations}

Funding This research did not receive any specific grant from funding agencies in the public, commercial, or not-for-profit sector.

Conflict of interest The authors declare that they have no conflict of interest.

Ethics approval Due to the case report nature of the study, the consent of the Ethics Committee of $\mathrm{CH}$ de Brive was not required. Patient data collection were performed in accordance of the Declaration of Helsinki.

Informed consent The patient consent was obtained to publish the data.

Availability of data and materials All data generated and analysed during this case report are included in this manuscript.

Author contributions All authors contributed to data collection and analysis. The first draft of the manuscript was written by Caroline Streicher and all authors commented on previous versions and approved the final version of the manuscript.

\section{References}

1. Huang C, Wang Y, Li X, Ren L, Zhao J, Hu Y, et al. Clinical features of patients infected with 2019 novel coronavirus in Wuhan, China. Lancet. 2020;395(10223):497-506. https://doi. org/10.1016/S0140-6736(20)30183-5.

2. Wang D, Hu B, Hu C, Zhu F, Liu X, Zhang J, et al. Clinical Characteristics of 138 Hospitalized Patients with 2019 Novel Coronavirus-Infected Pneumonia in Wuhan, China. JAMA. 2020;323(11):1061-9. https://doi.org/10.1001/jama.2020.1585.

3. Zhang $\mathrm{C}, \mathrm{Wu} \mathrm{Z}$, Li JW, Zhao H, Wang GQ. The cytokine release syndrome (CRS) of severe COVID-19 and Interleukin-6 receptor (IL-6R) antagonist Tocilizumab may be the key to reduce the mortality. Int J Antimicrob Agents. 2020;29:105954. https ://doi.org/10.1016/j.ijantimicag.2020.105954.

4. McGonagle D, Sharif K, O'Regan A, Bridgewood C. The role of cytokines including interleukin-6 in COVID-19 induced pneumonia and macrophage activation syndrome-like disease. Autoimmun Rev. 2020;19(6):102537. https://doi.org/10.1016/j. autrev.2020.102537.

5. Wang J, Jiang M, Chen X, Montaner LJ. Cytokine storm and leukocyte changes in mild versus severe SARS-CoV-2 infection: Review of 3939 COVID-19 patients in China and emerging pathogenesis and therapy concepts. J Leukoc Biol. 2020. https ://doi.org/10.1002/JLB.3COVR0520-272R.

6. Kotch C, Barrett D, Teachey DT. Tocilizumab for the treatment of chimeric antigen receptor $\mathrm{T}$ cell-induced cytokine release syndrome. Expert Rev Clin Immunol. 2019;15(8):813-22. https ://doi.org/10.1080/1744666X.2019.1629904.

7. Liu B, Li M, Zhou Z, Guan X, Xiang Y. Can we use interleukin-6 (IL-6) blockade for coronavirus disease 2019 (COVID19)-induced cytokine release syndrome (CRS)? J Autoimmun. 2020;10:102452. https://doi.org/10.1016/j.jaut.2020.102452.

8. Fu B, Xu X, Wei H. Why tocilizumab could be an effective treatment for severe COVID-19? J Transl Med. 2020;18(1):164. https://doi.org/10.1186/s12967-020-02339-3.

9. Ortiz-Martínez Y. Tocilizumab: a new opportunity in the possible therapeutic arsenal against COVID-19. Travel Med Infect Dis. 2020. https://doi.org/10.1016/j.tmaid.2020.101678.

10. Fioravanti A, Porcelli B, Terzuoli L, Bacarelli MR, Tenti S, Cheleschi S. Tocilizumab, adipokines and severe complications of COVID-19. Clin Drug Investig. 2020. https://doi. org/10.1007/s40261-020-00950-2.

11. Luo P, Liu Y, Qiu L, Liu X, Liu D, Li J. Tocilizumab treatment in COVID-19: a single center experience. J Med Virol. 2020. https://doi.org/10.1002/jmv.25801.

12. Xu XL, Han MF, Li TT, Sun W, Wang DS, Fu BQ, et al. Effective treatment of severe COVID-19 patients with tocilizumab. ChinaXiv. 2020;202003(00026):V1.

13. Di Giambenedetto S, Ciccullo A, Borghetti A, Gambassi G, Landi F, Visconti E, et al. GEMELLI AGAINST COVID-19 group (members are listed in the acknowledgments section). Off-label use of tocilizumab in patients with SARS-CoV-2 infection. J Med Virol. 2020. https://doi.org/10.1002/jmv.25897.

14. Guaraldi G, Meschiari M, Cozzi-Lepri A, Milic J, Tonelli $\mathrm{R}$, Menozzi M, et al. Tocilizumab in patients with severe COVID-19: a retrospective cohort study. Lancet Rheumatol. 2020;2(8):e474-e484484. https://doi.org/10.1016/S2665 -9913(20)30173-9.

15. Michot JM, Albiges L, Chaput N, Saada V, Pommeret F, Griscelli F, et al. Tocilizumab, an anti-IL6 receptor antibody, to treat COVID-19-related respiratory failure: a case report. Ann Oncol. 2020. https://doi.org/10.1016/j.annonc.2020.03.300.

16. Pipeline Review. Tocilizumab improves significantly clinical outcomes of patients with moderate or severe COVID-19 
pneumonia. April 28, 2020. https://pipelinereview.com/index .php/2020042874458/Antibodies/Tocilizumab-improves-signi ficantly-clinical-outcomes-of-patients-with-moderate-or-sever e-COVID-19-pneumonia.html. Accessed 10 Aug 2020.
17. Zhang S, Li L, Shen A, Chen Y, Qi Z. Rational use of tocilizumab in the treatment of novel coronavirus pneumonia. Clin Drug Investig. 2020;40(6):511-8. https://doi.org/10.1007/s40261-020-00917 -3 . 